\title{
Childhood education in Pakistan
}

\author{
Mukammil Shah Yousafzai \\ De Laas Gul Welfare Program
}

\section{Purpose}

The core purpose of the paper to identify the key problems of early education in Pakistan. It's also often referred to as preschool, pre-kindergarten, day care, nursery school or early education. No matter the name, each serves the same Pakistani children schools try to prepare young children for their transition into elementary school.

2 Problem at hand. It is mandated in the Constitution of Pakistan to provide free and compulsory education to all children between the ages of 5-16 years and enhance adult literacy. With the 18th constitutional amendment the concurrent list which comprised of 47 subjects was abolished and these subjects, including education, were transferred to federating units as a move towards provincial autonomy.

The year 2015 is important in the context that it marks the deadline for the participants of Dakar declaration (Education For All [EFA] commitment) including Pakistan. Education related statistics coupled with Pakistan's progress regarding education targets set in Vision 2030 and Pakistan's lagging behind in achieving EFA targets and its Millennium Development Goals(MDGs) for education call for an analysis of the education system of Pakistan and to look into the issues and problems it is facing so that workable solutions could be recommended.

\section{Methods}

The data collection through survey from the educationist, teachers, policy makers and key informants to find out the solutions.

3. Results (informative abstract only).

Problems: The issues lead to the comprehension of the problems which are faced in the development of education system and promotion of literacy. The study outlines seven major problems such as:

i) Lack of Proper Planning: Pakistan is a signatory to MDGs and EFA goals. However it seems that it will not be able to achieve these international commitments because of financial management issues and constraints to achieve the MDGs and EFA goals.

ii) Social constraints: It is important to realize that the problems which hinder the provision of 


\section{9-31 March 2019 in Prague, Czech Republic}

education are not just due to issues of management by government but some of them are deeply rooted in the social and cultural orientation of the people. Overcoming the latter is difficult and would require a change in attitude of the people, until then universal primary education is difficult to achieve.

iii) Gender gap: Major factors that hinder enrolment rates of girls include poverty, cultural constraints, illiteracy of parents and parental concerns about safety and mobility of their daughters. Society's emphasis on girl's modesty, protection and early marriages may limit family's willingness to send them to school. Enrolment of rural girls is $45 \%$ lower than that of urban girls; while for boys the difference is $10 \%$ only, showing that gender gap is an important factor.

iv) Cost of education: The economic cost is higher in private schools, but these are located in richer settlements only. The paradox is that private schools are better but not everywhere and government schools ensure equitable access but do not provide quality education.

v) War on Terror: Pakistan's engagement in war against terrorism also affected the promotion of literacy campaign. The militants targeted schools and students; several educational institutions were blown up, teachers and students were killed in Balochistan, KPK and FATA. This may have to contribute not as much as other factors, but this remains an important factor.

vi) Funds for Education: Pakistan spends 2.4\% GDP on education. At national level, $89 \%$ education expenditure comprises of current expenses such as teachers' salaries, while only $11 \%$ comprises of development expenditure which is not sufficient to raise quality of education.

vii) Technical Education: Sufficient attention has not been paid to the technical and vocational education in Pakistan. The number of technical and vocational training institutes is not sufficient and many are deprived of infrastructure, teachers and tools for training. The population of a state is one of the main elements of its national power. It can become an asset once it is skilled. Unskilled population means more jobless people in the country, which affects the national development negatively. Therefore, technical education needs priority handling by the government.

Poverty, law and order situation, natural disasters, budgetary constraints, lack of access, poor quality, equity, and governance have also contributed in less enrolments.

\section{Conclusion}




\section{9-31 March 2019 in Prague, Czech Republic}

The reforms required in the education system of Pakistan cannot be done by the government alone, public-private participation and a mix of formal as well as non-formal education can pull out majority of country's population from illiteracy. Similarly, to make the youth of the country an asset, attention should also be paid to vocational and technical training.

- The existing infrastructure is not being properly utilized in several parts of the country.

- There are various challenges that include expertise, institutional and capacity issues, forging national cohesion, uniform standards for textbook development, and quality assurance.

- The faculty hiring process is historically known to be politicized. It is because of this that the quality of teaching suffers and even more so when low investments are made in teachers' training. As a result teachers are not regular and their time at school is not as productive as it would be with a well-trained teacher.

- Inside schools there are challenges which include shortage of teachers, teacher absenteeism, missing basic facilities and lack of friendly environment.

- Out of school challenges include shortage of schools, distance - especially for females, insecurity, poverty, cultural norms, parents are reluctant or parents lack awareness.

Education is a systematic process of establishing the pillar of the society. It plays a very important role in the progress of any country around the world. Early Childhood Education (ECE) is a branch of education theory which relates to the teaching of young children (formally and informally) up till the age of about eight years. Its time of remarkable brain growth, these years lay the foundation for subsequent learning and development. People in the 6th largest country of the world are unable to get the basic education.

Various researches have proved that first few years of life are particularly important for the development of the child. Development of all domains and learning occur faster in these years than that of any other part of the life. The main challenging to the implementation of ECE in Pakistan is that the negative impact of limited access to education and its poor quality is disproportionately born by poor and marginalised children as well as families surviving in poverty tend to focus on keeping fed; rather than education. Other developmental domains such as psycho-social, emotional and physical skill are mostly neglected. Same as, early years are significantly important for cognitive abilities and the development of the brain capacity of a child as well.

Pre-school and child care centers play very important role in promoting the social and intellectual development of children. Moreover, through early childhood education child can easily develop his interpersonal skills through his interaction and the particular environment. The most striking feature of Pakistan's primary education system is its inherent inequalities. The ratio of gender discrimination is a cause which is projecting the primary school ratio of boys $\&$ girls which is 10:4 respectively. For the last few years there has been an increase in the growth of private schools that not only harms the quality of education but creates a gap among haves and have-not. The educational system of Pakistan is based on unequal lines. Medium of education is 


\section{9-31 March 2019 in Prague, Czech Republic}

different in both, public and private sectors. This creates a sort of disparity among people, dividing them into two segments. One division is on the basis of English-medium language while the other is Urdu-medium language.

With a net primary enrolment rate of $57 \mathrm{pc}$, there are an estimates 7 millions primary aged children are out-of school, mostly due to non-existence of school (as some live in remote or farflung area), absence of teacher and/or learning material or other reasons of the children who do not attend school, given that most $(63 \mathrm{pc})$ of the population living in rural area in relatively modest condition, but do not obtained quality education.

As a result of statistical analysis overall in Pakistan still over 27 million children out of school, pre-primary age group (3-5 years) 50pc children of Punjab out of the school, in Balochistan the ratio of out of school children is 78pc, in Sindh 61pc, in KP 65pc children are still out of school. Overall literacy rate of Pakistan is $54 \mathrm{pc}$ in which $66.25 \mathrm{pc}$ male and $41.74 \mathrm{pc}$ are female. According the report of UNESCO in 2014, Pakistan has the second highest (after Nigeria) population of out-of-school children in the world, with almost five and half million school-aged children not accessing to school and 72pc of school-aged children enroll in school. This is an improvement compared to two decades ago, when only 58pc of children enrolled in school. One of key goals of the Education For All deceleration is for countries to achieve a primary enrollment target of at least 95 pc by 2015 . While Pakistan is rated as very far from target (with an enrollment rate below 80pc), it is also rated as having relatively strong progress over the last two decades.(UNESCO, 2014)

Research show that if the healthy environment is provided to the children, they can learn at faster pace. Teachers play important role in the whole process. They must be familiarise and should have sound qualification to fulfill learning needs of children. If teachers are familiarised with the principles of love, kindness and care, they can easily teach students at primary level with the help of different pedagogies. However, professionally more trained people can educate the people to build a good nation. The allocation of funds for education is very low. It is only 1.5 to 2.0 percent of the total GDP. It should be around 7pc of the total GDP. We should follow the example of Malaysian government which earmarks about 35 percent of its GDP to education sector. We need to push for greater public investment in education in Pakistan.

\section{Solutions}

There is a need for implementation of national education policy and vision 2030 education goals. An analysis of education policy suggests that at the policy level there are several admirable ideas, but practically there are some shortcomings also. 


\section{9-31 March 2019 in Prague, Czech Republic}

It may not be possible for the government at the moment to implement uniform education system in the country, but a uniform curriculum can be introduced in educational institutes of the country. This will provide equal opportunity to the students of rural areas to compete with students of urban areas in the job market.

Since majority of Pakistani population resides in rural areas and the access to education is a major problem for them, it seems feasible that a balanced approach for formal and informal education be adopted. Government as well as non-government sector should work together to promote education in rural areas.

The government should take measures to get school buildings vacated which are occupied by feudal lords of Sindh, Balochistan and Punjab. Efforts should be made to ensure that proper education is provided in those schools.

The federal government is paying attention to the vocational and technical training, but it is important to make the already existing vocational and technical training centres more efficient so that skilled youth could be produced.

Since education is a provincial subject, the provincial education secretariats need to be strengthened. Special policy planning units should be established in provinces' education departments for implementation of educational policies and formulation of new policies whenever needed. The provincial education departments need to work out financial resources required for realising the compliance of Article 25-A.

Federal Government should play a supportive role vis-à-vis the provinces for the early compliance of the constitutional obligation laid down in Article 25-A. Special grants can be provided to the provinces where the literacy rate is low.

Pakistan is not the only country which is facing challenges regarding promotion of literacy and meeting EFA and MDGs commitments. Education remains a subject which is paid least attention in the whole South Asian region. UNDP report 2014 suggests that there has been an improvement in other elements of human development such as life expectancy, per capita income and human development index value (in past 3 years); but there has been no progress in the number of schooling years. The expected average for years of schooling in 2010 was 10.6 years but the actual average of schooling remained 4.7 for all South Asian countries. In the year 2013 the expected average of number of years increased to 11.2 but the actual average of years of schooling of South Asian countries remained 4.7. Regional cooperation mechanism can also be developed to promote literacy in South Asian region. Sharing success stories, making country-specific modifications and their implementation can generate positive results.

\section{Recommendations}




\section{International Conference on Future of Teaching and Education}

\section{9-31 March 2019 in Prague, Czech Republic}

* Technical education should be made a part of secondary education. Classes for carpentry, electrical, and other technical education must be included in the curriculum.

* Providing economic incentives to the students may encourage the parents to send their children to school and may help in reducing the dropout ratio.

* Local government system is helpful in promoting education and literacy in the country. In local government system the funds for education would be spent on a need basis by the locality. * Corruption in education departments is one of the factors for the poor literacy in the country. An effective monitoring system is needed in education departments.

* For any system to work it is imperative that relevant structures are developed. Legislation and structure should be framed to plan for the promotion of education in the country. After the 18th amendment the education has become a provincial subject, therefore, the provinces should form legislations and design educational policies which ensure quality education.

* Unemployment of educated men and women is a major concern for Pakistan. There should be career counselling of the pupils in schools so that they have an understanding of job market and they can develop their skills accordingly.

* Counselling of parents is required, so that they can choose a career for their child which is market friendly.

* There are two approaches to acquiring education: First, which is being followed by many in Pakistan is to get education to earn bread and butter. The second approach is to get education for the sake of personal development and learning. This approach is followed by affluent and economically stable people who send their children to private schools and abroad for education. The problem arises when non-affluent families send their children to private schools, and universities. This aspiration for sending children for higher education is wrong, because the country does not need managers and officers only. There are several other jobs where people are needed. Hence the mind-set of sending one's children to university only for becoming officers and managers needs to be changed.

References:

Human Development Report 2014 “Sustaining Human Progress: Reducing Vulnerabilities and Building Resilience," United Nations Development Programme (UNDP) (New York: UNDP, 2014).

Mehnaz Aziz et al, "Education System Reform in Pakistan: Why, When, and How?" IZA Policy Paper No. 76, January 2014 (Institute for the Study of Labor, 2014), P 4.

Annual Report: Pakistan Education Statistics 2011-12, National Education Management Information System Academy of Educational Planning and Management, Ministry of Education, Trainings \& Standards in Higher Education, Government of Pakistan, (Islamabad, AEPAM, 2013).

Economic Survey of Pakistan 2014, Ministry of Finance, Government of Pakistan. 


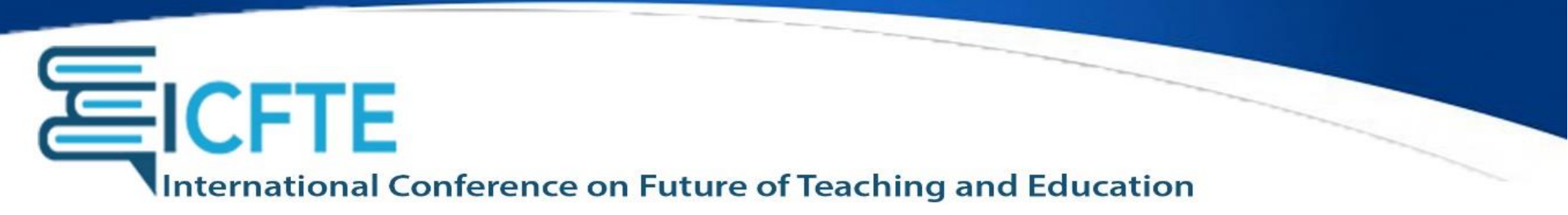

\section{9-31 March 2019 in Prague, Czech Republic}

Pakistan: Education for All 2015 National Review, Ministry of Education, Trainings and Standards in Higher Education Academy of Educational Planning and Management Islamabad, Pakistan June, 2014 (available at : http://unesdoc.unesco.org/images/0022/002297/229718E.pdf). Maliha Naveed, Reasons of Low Levels of Education in Pakistan, Pakistan Herald, January 03, 2013 (available at: http://www.pakistanherald.com/articles/reasons-of-low-levels-of-educationin-pakistan-3065).

"Pakistan may miss EFA goals by 2015-16: Report," Daily Nation, October, 3, 2014. 